\title{
APRENDIZAGEM ORGANIZACIONAL NO DESEMPENHO DOS LÍDERES: O QUE INFORMAM AS PESQUISAS
}

\section{ARTIGO ORIGINAL}

SCHECHNER, Ylana Miller ${ }^{1}$

NAVARRO, Ignacio Gallardo ${ }^{2}$

LIMA-BAPTISTA, Erica Cindra de ${ }^{3}$

SCHECHNER, Ylana Miller. NAVARRO, Ignacio Gallardo. LIMA-BAPTISTA, Erica Cindra de. Aprendizagem Organizacional no desempenho dos líderes: o que informam as pesquisas. Revista Científica Multidisciplinar Núcleo do Conhecimento. Ano 04, Ed. 08, Vol. 05, pp. 113-134. Agosto de 2019. ISSN: 2448-0959, Link de acesso: https://www.nucleodoconhecimento.com.br/administracao/desempenho-doslideres

\section{RESUMO}

O presente artigo de revisão proporciona ao leitor uma síntese do estudo produzido, no período de 2009 a 2019, sobre aprendizagem organizacional no desempenho dos líderes. É um tema que vem assumindo um papel importante nas organizações como

${ }^{1}$ Doutoranda em Educação, Universidad SEK - Chile, Mestre em Administração pelo IBMEC (2009), com Pós-Graduação em Marketing pelo IBMEC (2006) e PósGraduação em Gestão de Recursos Humanos pela FABES (1995). Graduada em Pedagogia pela UERJ (1988) e Administração de Empresas pela Universidade Cândido Mendes (1992).

2 Doutorado em Psicologia - Universidade do Chile. Especialista em Psicologia Esportiva na Universidade Diego Portales - Universidade Islas Baleares, Chile Espanha (dupla titulação).

${ }^{3}$ Doutora em Psicologia social - Universidade do Estado do Rio de Janeiro UERJ. 
vantagem competitiva. Como complemento, são explicitados a relevância da aprendizagem para as organizações que investem em evolução e gestão da mudança, tendendo a promover lições que formam as teorias de ação dos indivíduos nas organizações. Trata-se de trabalho investigativo de natureza qualitativa, exploratória e descritiva cujas fontes de dados remontam às produções científicas, publicadas nos últimos 10 anos, através dos procedimentos de busca da Revisão Integrativa da Literatura (RIL), acessando-se bases de dados, Cochrane Library, Portal Capes, BVS, Lilacs, Campbell Colaboration. A investigação seguiu para artigos publicados em periódicos especializados e em relatórios de novas pesquisas. A cada base de dados, foram organizados procedimentos costumeiros em pesquisas de revisão, elucidando os critérios de inclusão e de exclusão. Ao todo foram encontrados, cerca 300 textos no formato de artigos, Teses e Dissertações. Desse conjunto, 10 foram incluídos e criticamente analisados, sustentando-se as hipóteses previamente formuladas. Foram identificadas lacunas conceituais e pouca produção científica, o que pode comprometer a escolha das melhores práticas baseadas em evidência científica no que tange aos efeitos/vantagens da aprendizagem organizacional no desempenho dos líderes.

Palavras-chave: aprendizagem organizacional, desempenho dos líderes, revisão integrativa da literatura.

\section{INTRODUÇÃO}

Em meio às pressões e às demandas atuais, as empresas são chamadas a responder questionamentos que vão além suas rotineiras responsabilidades na área econômica em função do dos obstáculos sociais, econômicos e ambientais recaídos sob humanidade, (FRANKLIN, 2008; KREITLON, 2004; OLIVEIRA, 2008; SCHOMMER, 2009). Neste contexto, um dos temas abordados é o de gestão do capital humano e aprendizagem organizacional. Cada vez mais as empresas investem na gestão do capital humano e na aprendizagem organizacional para se manterem competitivas na sua área de atuação. Neste sentido, o compartilhamento de conhecimentos e o aprendizado vêm assumindo um papel importante nas organizações como vantagem competitiva. (DAVENPORT \& PRUSAK, 1998). 
Nas instituições de conhecimento, as pessoas expandem de modo continuo a qualidade de atingir metas com os resultados desejados, nos quais novas formas de pensar são encorajadas, e assim pessoas se fazem continuamente parte do aprender coletivo (SENGE, 1999). As organizações que aprendem têm como diferencial as seguintes atividades: a solução de problemas de forma sistemática, a experimentação de abordagens novas; o aprendizado com experiências individuais, junto às práticas alheias e a partilha de conhecimentos, com eficiência, em toda a organização. A eficácia na gestão do aprendizado ocorre mediante a criação de sistemas e processos que integrem essas atividades (GARVIN, 2001). A instituição que aprende é a que possibilita o recurso de habilidades para a criação, adquirindo e partilhando conhecimentos, sendo capaz de fornecer novos comportamentos que resultem em uma reflexão conhecimentos e ideias inéditas.

As empresas são solicitadas para que criem oportunidades de compartilhamento de conhecimentos que se apresenta como uma ferramenta importante que interfere diretamente na formação de seus líderes. Segundo Robbins (2014), liderança é habilidade de influenciar um grupo ao alcance de metas e objetivos. Líderes tem a possibilidade do surgimento natural ou por indicação formal no meio de um grupo. $\mathrm{O}$ autor ressalta que as principais habilidades de um líder são: inteligência, autoconfiança, carisma, capacidade de decisão, entusiasmo, coragem e integridade.

O que se refere a temática proposta esse estudo, aprendizagem Organizacional no desempenho dos líderes, há diversas teorias sobre aprendizagem organizacional, contudo, há também escassez de proposições empíricas da relação do tema e do desempenho da liderança (Baker \& Sinkula, 1999). No entanto o estudo desta temática vem ampliando proporções no campo organizacional, principalmente pela relevância da aprendizagem para as organizações que investem em evolução e gestão de mudanças, tendendo promover lições que formam as teorias de ação dos indivíduos nas organizações, sendo apresentada como estratégia para as empresas bem como uma vantagem competitiva para empresas. (KHANDEKAR \& SHARMA, 2006; PIETRO \& REVILLA, 2006). 
A aprendizagem organizacional pode propiciar uma alavancagem no desempenho dos líderes, expandindo as suas competências na gestão de equipes resultando uma combinação de experiências de vida e de trabalho. Cada vez mais se defende que as habilidades do líder podem ser aprendidas. A liderança não é genética e nem decifrada em códigos, um conjunto observável de talentos e capacidades que pode ser usado onde se está. E qualquer talento pode ser reforçado, alimentado e galvanizado se houver motivação e desejo, juntamente com a prática do feedback, modelos de ação e treinamento.

Desta forma, os estudos apresentados nesta pesquisa se tornam relevante porque trará subsídios e indicadores para profissionais da área de recursos humanos focados no desenvolvimento humano e organizacional, líderes de organizações que atuam em diversos segmentos, consultores e professores, que estudam, criam, definem e programam processos de aprendizagem organizacional como destaque no desenvolvimento de líderes em empresas.

\section{REFERENCIAL TEÓRICO}

A conceituação dos extratos na modalidade de Pesquisa de Revisão de Literatura não apresenta consenso quanto ao uso e equivalência com a terminologia. Embora se rotule genericamente a maioria das pesquisas como sendo de Revisão Sistemática, há um tipo específico para cada pesquisa fim em questão. E, a partir das especificidades, seus resultados abrem novos caminhos à teorias e aplicações técnicas, como as chamadas Práticas Baseadas em Evidências (PBE), por exemplo. Hoje se utiliza da Pesquisa de Revisão em diversas instituições, como no trânsito, por exemplo, além da escola, organizações corporativas e, reconhecidamente, em diversos outros ambientes. (BOTELHO, CUNHA \& MACEDO, 2011).

Nesta investigação foi usado o critério desenvolvido a partir do Centro Cochrane do Brasil que subsidiou os estudos mais recentes produzidos pelo Grupo Ânima de Estudo. (CUNHA \& COLS, 2014) 
A pesquisa de Revisão Sistemática se destaca na hierarquia das evidências científicas, indicando maior grau de confiança e validade; traz a proposta de poder envolver diversos estudos científicos; compreende a ideia da interdisciplinaridade; e pode ser usada por diversas áreas além da Medicina, sua mais antiga e maior expressão.

$\mathrm{Na}$ pesquisa de Revisão de Literatura Bibliográfica Sistemática Integrativa (RLBSI=RIL) há uma performance bibliométrica, com características exploratórias, descritivas e qualitativas. Diante das chamadas evidências científicas, por exemplo, foca em estudos sistemáticos primários de fonte em pesquisa eletrônica preferencialmente. Na RSL compreendem-se os subtipos metodológicos como Sistemática, Meta-análise, Revisão Qualitativa e também Integrativa (Cunha \& Cols., 2014, p.1), que revela o "state of art" do tema em pauta.

A RIL possui amplitude nas buscas de resultados, mas resguarda as especificidades do que coleta. Dentre as Revisões permite a inclusão de estudos experimentais e não experimentais para uma compreensão mais completa do fenômeno analisado. O objetivo nodal é estar diante de inúmeras propostas complexas e poder produzir um cenário coerente, relevante e consistente. Este tipo de estudo combina dados de natureza teórica e empírica, também incluindo propósitos diversos: definição de conceitos, revisão de teorias e evidências, e análise de problemas metodológicos de um tópico particular. (SOUZA, SILVA \& CARVALHO, 2010).

Há na produção da RIL há uma sequência. A "definição da pergunta" é ímpar na sua elaboração, já que proporciona direção para a execução das demais atividades correlacionadas ao processo, incluindo a definição dos participantes, intervenções para avaliação e os resultados a serem observados. Uma revisão é planejada para responder uma pergunta específica que utiliza métodos para identificar, selecionar e avaliar criticamente os estudos, e para coletar e analisar os dados destes estudos incluídos. (ROTHER, 2007).

A RIL identifica, analisa, e sintetiza resultados de pesquisas, indicando o panorama e em se tratando de aspectos clínicos, pode-se pautar os melhores cuidados, havendo 
aí a presença de um espírito crítico e não somente protocolar. (SOUZA, SILVA \& CARVALHO, 2010)

Esta pesquisa propõe se embasar em estudos de autores e pesquisadores que investigam o tema sob as perspectivas da aprendizagem organizacional, identificando a sua relação com o desempenho dos líderes nas empresas.

Pesquisam que elucidam a relação entre aprendizagem e desempenho organizacional são desenvolvidos por Baker \& Sinkula, 1999; Cantalone, Cavusgil \& Zhao, 2002; Rhee, Park \& Lee, 2010) e brasileiros, Leopoldino \& Loiola, 2010; Perin, Sampaio e Faleiro, 2004). Nesses estudos a aprendizagem organizacional e sua influência no desempenho da liderança pode ser mensurada através de indicadores de desempenho, que estão presentes nas diversas áreas do ambiente organizacional. Há literatura especializada que contempla dados qualitativos desta ferramenta estruturada de gestão. As organizações devem ser dirigidas por indicadores, que contribuem para um controle e acompanhamento, dando um tratamento aos diversos elementos de uma empresa, dentre eles a modelagem relacionada ao capital humano. (MACIEIRA, 2015).

Novas pesquisas observam a relevância da aprendizagem organizacional, no entanto, pouco se discute e evidência de seus benefícios e influência no desempenho de líderes empresariais. Então, como as práticas de aprendizagem, sejam elas reuniões, treinamento e desenvolvimento, avaliação de desempenho, coaching, dentre outras podem contribuir para o desempenho dos líderes?

Algumas perguntas complementares contribuem para a reflexão, sendo elas: qual a relação dos conceitos de aprendizagem organizacional com o desempenho da liderança?

\section{MATERIAIS E MÉTODOS}

Trata-se de um estudo exploratório, qualitativo e descritivo, fazendo o uso de métodos de Revisão Integrativa da Literatura (RIL), operacionalizada por meios de busca 
eletrônica, a níveis nacionais e internacionais. Foram acessadas as bases de dados Psico Info, Cochrane Library, Portal Capes, BVS, Lilacs, Campbell Colaboration - com o foco de padronizar a linguagem de busca, dentre as bases de dados eletrônicos, fez-se uso dos descritores de saúde DeCS e Mesh. Neste processo de meio de busca, os descritores e termos livres foram escritos "Aprendizagem Organizacional" e "Desempenho dos Líderes", “Leadership Performance" e "Organizational Learning".

Os descritores foram usados isoladamente ou combinados em conjunto com o auxílio dos operadores booleanos AND e OR, segundo as especificidades de cada base de dados selecionada, no período de novembro de 2018 a janeiro de 2019.

A pergunta formulada que direciona esta pesquisa é: o que informam as pesquisas sobre Aprendizagem Organizacional no desempenho dos líderes? E o questionamento complementar é: qual o nível de eficácia da Aprendizagem organizacional no desempenho de liderança?

O meio de pesquisa considerou o mesmo caminho que as propostas de pesquisas de revisão, sendo estas: a) explanação do problema a ser buscado; b) formulação da pergunta essencial da pesquisa; c) rastreamento nas bases de dados possíveis; d) coleta e análise das respostas das pesquisas geradas; e) discussão dos resultados obtidos e, por fim f) demonstração do quadro sintético dos resultados da Revisão Sistemática da Literatura.

\subsection{CRITÉRIOS DE INCLUSÃO E DE EXCLUSÃO: PROCEDIMENTOS}

As RIL obtidas foram analisadas de acordo com os critérios de inclusão. Os títulos e resumos de artigos foram selecionados e analisados, considerados aptos a inclusão na Revisão Sistemática aquele que obteve resposta afirmativa em todas as 03 (três) questões seguintes:

1. O conteúdo do artigo aborda pesquisas sobre aprendizagem organizacional no desempenho dos líderes? 
2. As respostas conclusivas das buscas evidenciavam o grau de eficácia da aprendizagem organizacional no desempenho de liderança?

3. Os resultados das buscas estão de acordo com os objetivos esperados pelos pesquisadores?

Foram exclusos da pesquisa os estudos que não obtiveram resposta positiva às questões, não correspondendo ao interesse da pergunta prévia.

Com as informações coletadas e detalhadamente retiradas dos artigos analisados, foi possível organizar os dados para efetuar a apresentação de maneira, conforme apresentado a seguir.

\subsection{COLETA E ANÁLISE DOS DADOS}

Em prima, cada RIL foi avaliada de acordo com os títulos, seguida de uma leitura geral do resumo, sofrendo eliminação quando não havia enquadro aos critérios de busca determinados.

A investigação ocorreu em artigos publicados em periódicos especializados e em relatórios de pesquisas recentes. A cada base de dados, foram organizados procedimentos costumeiros em pesquisas de revisão, elucidando os critérios de inclusão e de exclusão. Ao todo foram encontrados, cerca 300 textos no formato de artigos, Teses e Dissertações. Desse conjunto, 10 foram incluídos e criticamente analisados, sustentando-se as hipóteses previamente formuladas.

Os dados foram extraídos da Revisão Sistemática da Literatura, considerando a perspectiva qualitativa, e dispostos no formato de relatório descritivo, conforme tabela a seguir. Para o resguardo dos dados da RIL, foram criados quadros com as seguintes informações: autores, ano de publicação, número de participantes, resultados. 


\section{RESULTADOS E DISCUSSÃO}

Quadro 1- Resultado

\begin{tabular}{|l|l}
\hline Autores & $\begin{array}{l}\text { Tipo de Pesquisa /Fatores e Variáveis de } \\
\text { Desempenho/objetivos }\end{array}$
\end{tabular}

Faustin, C. M. S. A. Dissertação/ identificar o entrosamento das (2017) competências de Coaching do Líder com os resultados atitudinais e comportamentais dos colaboradores, buscando compreender como a prática contribui para um melhor Empenhamento Afetivo e Desempenho dos colaboradores.

Santos, J. F. O. ( 2017) Dissertação/ (a) averiguar os processos de seguimento da mudança com o referencial teórico-conceitual sobre liderança da alteração (ver capítulo 1); (b) verificar a analogia do processo de formação para a mudança com o referente teórico-concetual sobre avaliação da formação (ver capítulo 2); (c) reconhecer os objetivos dos trabalhadores alvo da mudança sobre o envolvimento e o apoio promovidos pela liderança modificada; (d) identificar as percepções dos trabalhadores alvo da formação para a mudança sobre o seu uso em executar as alterações que foram solicitadas; e (e) identificar as propostas destes trabalhadores para uma melhor condução da mudança e da constituição da mudança em situações futuras semelhantes.

Rauber, M. J. (2017). Tese, Coaching de Socialização/ objetivo pesquisar o aproveitamento das vantagens do Coaching como um instrumento de desenvolvimento pessoal, utilizando-o como uma estratégia de acolhimento e integração no nível de socialização de atuais colaboradores por intermédio de uma metodologia de aplicação. 
Pereira, B. C. B. (2016) Dissertação/ Identificar práticas empreendedoras como estratégia de resposta aos desafios organizacionais relacionados à gestão de projetos.

Hörbe, T.A. N (2016) Tese/ examinar a influência da Estrutura Organizacional e do estilo de liderança no Aprendizagem Organizacional

Lins, M. P. B.E. 2011 Dissertação/ testar um modelo preditivo de competências de liderança no contexto de equipes permanentes de trabalho.

Gang Wang, Oh, I.-S., Artigo/ Analisar a associação entre a liderança Courtright, S. H., \& transformacional e o desempenho dos funcionários.

Colbert, A. E. (2011).

ADRIAN,G. S. P (2011) Dissertação/ invetsigar o influxo da liderança no desenvolvimento de atendentes de contact centers no Brasil no ano de 2010, sob a ótica dos liderados - os atendentes - em relação aos seus líderes - os supervisores estudo de caso.

Yuhee Jung \& Artigo/ examinar as inter-relações entre liderança de alta

Norihiko

Takeuchi (2010) gerência, cultura organizacional e práticas de recursos humanos $(\mathrm{RH})$, e seus efeitos associativos no desempenho organizacional.

Rego, A. Pina, M e C. Artigo/ experimentar um paradigma preditivo de Clegg, S , 2010 competências de liderança nas circunstâncias de equipes permanentes de trabalho

Muhammad Rafiq Artigo/ explorar o estilo de liderança, a cultura Awan, Khalid organizacional e o comprometimento com o trabalho nas Mahmood, (2010) bibliotecas universitárias do Paquistão e as relações entre eles.

Fonte: Autor.

Admitindo a pertinência da aprendizagem organizacional, o presente estudo procurou analisar quais as dimensões de impressão da aprendizagem organizacional no 
desenvolvimento dos líderes. Face à realidade atual, é crucial que as organizações estejam preparadas para enfrentar a mudança surgindo a necessidade de fortalecerem as suas capacidades de resposta a estas mudanças. É, neste sentido, que urge a necessidade de desenvolver a capacidade de aprendizagem das organizações dado que este é o requisito básico para que estas consolidem competências profissionais, o trabalho em equipe ou o estabelecimento das relações democráticas com a liderança.

Neste contexto e considerando que o único meio pelo qual uma organização pode se transformar numa organização que aprende e o desempenho de líderes, surgiu a necessidade de realizar um estudo bibliográfico para analisar a relação entre a liderança e a aprendizagem organizacional. Neste sentido realizou-se uma RIL verificando quais os pilares em que assenta a aprendizagem organizacional, o estilo de liderança, o nível de desempenho da aprendizagem, que serão apresentadas a seguir.

No que se refere à aprendizagem organizacional e ao desempenho da liderança, a pesquisa de Rauber, (2017) teve como objetivo explorar o estabilidade dos benefícios do coaching como um instrumento de desempenho pessoal, utilizando-o como uma técnica de recepção e integração no estágio do encontro na socialização de novos colaboradores por meio de uma metodologia de aplicação.

Em decorrência da tese, foi desenvolvido o Coaching de Socialização como um guia de aplicação pela área de GRH nos programas de recepção e de integração, buscando por intermédio da socialização, novos colaboradores. Tal pesquisa foi designada como inédita, propondo uma identificação o espaço no qual o coaching não participava na fase de encontro da socialização dos novos colaboradores como um instrumento de desenvolvimento pessoal - a mesma foi identificada na pesquisa bibliográfica e diálogos com gestores de $\mathrm{RH}$. A tese apresenta uma revisão literária que aponta a evolução da GRH e as suas tendências essenciais, discorrendo sobre socialização em níveis, explorando o Coaching um intermédio para o desenvolvimento pessoal e e sua demanda no ambiente organizacional, assim encontrando as 
evidências de que a aplicação do Coaching de Socialização é uma novo encargo para a área.

A tese também apresenta as ligações entre o processo de Coaching e a área de GRH, especialmente a socialização na fase de encontro, que conceberam a adaptação de ferramentas de apoio ao Coaching de Socialização como a Roda do Trabalho, a Grade de Metas no Trabalho e a Ecologia da Decisão no Trabalho. Nesse contexto, o Coaching de Socialização foi categorizado como uma estratégia de socialização distinta de caráter, e informal quanto ao meio; individualizada não sequencial e mutante quanto a capacidade; e em relação aos aspetos sociais, é uma técnica individualizada disjuntiva e uma tática legitimada de investimento. (JONES, 1986).

Junto ao desenvolvimento e à execução do Coaching de Socialização está a compreensão de que a área de GRH deve incentivar os novos colaboradores a desenvolverem o papel ativo na sua socialização desde sua entrada na organização. Dessa forma, com a utilização do Coaching de Socialização encoraja-se que os novos colaboradores sejam acolhidos, integrados e socializados, e também que se façam acolhidos, integrados e socializados.

Neste cotexto de coaching, liderança e aprendizagem organizacional Adrian (2011) analisou a intervenção da liderança no desempenho de atendentes de contact centers no Brasil em 2010, sob a visão dos atendentes, quanto aos seus líderes, os supervisores, a partir de um estudo de caso em uma organização líder deste mercado, com aproximadamente noventa mil funcionários, sendo esta a segunda maior empregadora privada do Brasil.

Assim, foi realizada a fundamentação teórica para a compreensão da liderança, do desempenho e da relação entre liderança e instituições, assim como a particularização sobre Contact Centers, procurando debater os meios essenciais de gestão de pessoas voltada ao desempenho e fatores influenciadores, além da liderança, dos resultados individuais e grupais. 
O modelo conceitual de pesquisa propôs a caracterização e identificação da liderança a partir da eleição de determinados tratamentos teóricos, sendo estes: estilos de liderança, abordagem contingencial e abordagem de nova liderança; caracterização do desempenho com objetivo em gestão e pessoalidade, influenciadores possível de desempenho; e, por fim, entender a atuação da liderança no desempenho individual na organização elegida.

O conjunto de resultados da pesquisa realizada com 270 atendentes indicou que em relação à liderança, a democracia é o dominante entre supervisores, com influência da abordagem contingencial e modelo de liderança participativa. Sobre o desempenho, nota-se que a presente organização mantém nível alto de controle e monitoramento sobre as respostas dos funcionários, com métodos avaliativos de desempenho que assistem o feedback do processo e a melhoria constante. Outrossim, 76,5\% dos respondentes acreditam que a organização faz com que os novos funcionários se sintam pertencentes à mesma, o que contribui de modo positivo para o sentimento de pertencimento e aumento da produtividade. Por fim, os resultados apontaram uma forte ligação de importância da atuação do líder, o com o resultado e desempenho individual dos atendentes da Contax, com 83,7\% dos correspondentes que concordam com a presente afirmação, e 73,3\% indicam que a atuação do líder como um dos três principais fatores de produção de maiores níveis de desempenho.

O trabalho é finalizado com a apresentação dos resultados alcançados, unidos a conclusões e sugestões para a produção de estudos que envolvem os conteúdos e o setor de Contact Centers, conceituando o tamanho deste mercado e importância deste para a geração de empregos no país.

Ainda em relação às competências de Coaching e Liderança, a pesquisa de Faustin (2017) teve como objetivo identificar a associação das habilidades de Coaching do Líder com as respostas de atitude e comportamento dos colaboradores, buscando compreender como a prática contribui para a melhoria do Empenhamento Afetivo e Desempenho dos colaboradores e analisando o relacionamento entre 0 Empenhamento Afetivo dos subordinados e o seu Desempenho Individual. Para o 
autor, no atual contexto econômico e social, as organizações devem adotar novas técnicas e táticas que permitam o atingimento de alto Desempenho, a fim de persistir no mercado concorrencial e determinar a sua competitividade.

O capital humano recebe seu destaque no cenário atual, tomando as competências individuais como fundamentais, buscando por inovações no campo de gestão de pessoas, visando o desenvolvimento profissional e pessoal, atingindo assim o desempenho pretendido para atingir os objetivos organizacionais a que se propõem.

O Líder que porta competências de Coaching é capaz de modular comportamentos e atitudes, assim como permite a criação de um elevado grau de empenho e confiança, potencializando e inspirando os seus seguidores, promovendo a dinâmica da equipe e grande desempenho. O Coaching torna-se um instrumento promotor do desenvolvimento das competências dos colaboradores. Este estudo foi realizado sob a forma de questionário, com 141 colaboradores pertencentes a instituições distintas.

Com base nas ideias acerca dos seus líderes, propôs-se um estudo sobre respostas atitudinais e comportamentais dos questionados. Os resultados demonstraram que as Competências de Coaching do Líder justificam 14\% do Empenhamento Afetivo, 5\% do Desempenho e assim como o fato do Empenhamento Afetivo clarificar aproximadamente $15 \%$ do Individual. Os resultados são representam a população, porém nos permitem considerar que Competências de Coaching do Líder obtém um importante papel nas respostas atitudinais e comportamentais dos colaboradores, colaborando para o desenvolvimento sustentável da organização. O Coaching é considerado uma prática emergente fundamental para a mudança nas organizações, obtendo reconhecimento por parte das mesmas quanto as suas potencialidades.

O estudo de Rego, A. Pina, M e C. Clegg, S, (2010), teve por objetivo avaliar e testar um modelo prognostico de competências de liderança de acordo com o contexto de equipes fixas de trabalho. A liderança foi definida como o processo de interação ética entre o gestor e a equipe, buscando alcançar objetivos em comum. Neste processo, há a diferenciação do gestor entre o papel formal e o responsável de especialidades diante a equipe. A vertente foi definida como as competências de liderança, medidas 
a partir da autoavaliação dos gestores e de suas equipes de trabalho, sendo esta uma heteroavaliação.

As variáveis anteriores foram em forma de horas de treinamento e uso de táticas de aprendizagem no trabalho. Foi testado o efeito moderador da motivação para aprendizagem com 377 gestores de três órgãos da Administração Pública Federal e 692 integrantes de equipes de trabalho. Os resultados foram coletados por meio de escalas de cálculo foram submetidos às análises fatoriais para validação psicométrica, e regressões simples ou múltiplas foram realizadas para testar as hipóteses propostas.

No sistema de autoavaliação de competências, quatro diferentes estratégias de aprendizagem (busca de ajuda interpessoal, aplicação prática, reflexão intrínseca e extrínseca, busca de ajuda em material escrito) foram eleitas para competências de liderança, mas não houve relação de predição entre o tempo de treinamento e a variável conceituada. No sistema de heteroavaliação de competências, apenas o tempo de treinamento e a tática de busca de ajuda interpessoal foram preditoras para práticas de liderança. As hipóteses relacionadas ao efeito moderador de motivação para aprendizagem foram rejeitadas, e discutiram-se os benefícios do estudo para políticas de desenvolvimento gerencial, assim como as limitações da investigação e uma agenda para novos estudos.

Com o propósito de examinar a influência da Estrutura Organizacional e do estilo de liderança na Aprendizagem Organizacional, Hörbe (2016) elaborou uma pesquisa de cunho descritivo, natureza quantitativa e qualitativa, realizada por meio de um estudo de caso em uma empresa do setor automobilístico, vencedora do Prêmio Nacional da Qualidade, no ano de 2015. Na fase quantitativa, participaram cerca de 50 colaboradores pertencentes a variadas posições hierárquicas da Unidade de Equipamentos de Construção da empresa citada, os quais receberam um questionário dos seguintes modelos: Escala de Aprendizagem Organizacional, desenvolvida por Goh e Richard (1997) e validada no Brasil, por Angelim e Guimarães (2003), Escala de Estrutura Organizacional, utilizada por Gaspary (2014), baseado nos estudos de 
Hage e Aiken (1967) e Nahm et al. (2003) e Escala de Avaliação do Estilo Gerencial desenvolvida por Melo (2004).

A etapa qualitativa sustentou a análise de documentos da empresa e entrevistas estruturadas com quatro gestores da Unidade de Equipamentos de Construção da empresa em questão, com um protocolo desenvolvido de acordo com os modelos citados. Os resultados quantitativos foram examinados por intermédio estatístico descritivo, teste T e ANOVA para testar diferença de média, Alpha de Cronbach para confiabilidade, Correlação de Person e Análise de Regressão. A Estrutura Organizacional obteve resultados de pesquisa que demonstraram que a organização é possuidora de uma estrutura matricial e descentralizada, com formalização e integração de altos níveis.

O estilo de liderança é voltado ao Relacionamento e Situacional de modo predominante, o que indica que as lideranças atuam com foco no relacionamento interpessoal, e sua atuação distingue-se de acordo com o perfil do funcionário. A Aprendizagem Organizacional obteve resultados que apresentaram que as práticas de gestão da empresa estão voltadas, em especial, a propiciar aos funcionários Clareza de Propósito e Missão organizacional, assim como uma cultura de encorajamento a experimentação e de novas ideias, práticas que refletem no envolvimento e comprometimento dos funcionários para resultados organizacionais de sucesso.

As análises de regresso múltiplo apresentaram dois sistemas válidos: a) a presença da variável Centralização-Tomada de Decisão, que exerce força de explanação no Fator 02 de Aprendizagem Organizacional e Incentivo da Liderança sob a ótica de inclusão na tomada de decisão e solução de problemas em equipe; b) a presença das variáveis Integração-Comunicação e Estilo de Liderança Situacional, que exercem força de justificativa para a Clareza de Propósito e Missão. Desta forma, percebe-se que a Estrutura Organizacional e o estilo de liderança praticam forte influência na Aprendizagem Organizacional, colaborando com indicativos para a literatura de Aprendizagem Organizacional e seus motivos prévios, assim como com colaborações para as atitudes gerenciais de organizações que pretendem crescer em suas metas, 
além da maturidade de gestão por intermédio da Aprendizagem Organizacional. Tal pesquisa foi desenvolvida com o propósito de examinar a influência da Estrutura Organizacional e do estilo de liderança na Aprendizagem Organizacional.

$\mathrm{Na}$ investigação realizada por Pereira (2016), a Gestão Estratégica de Pessoas é apontada como um dos grandes diferenciais que indicam a capacidade de adaptação ao mercado, assim como o benefício competitivo. $O$ autor defende as etapas da execução do método, no qual se dispõe categoricamente em Gestão Estratégica como Diferencial Competitivo; Competências Individuais; Treinamento e Desenvolvimento de Pessoas; Coaching e Mentoring e por último a Avaliação do Desenvolvimento Humano.

Yuhee Jung \& Norihiko Takeuchi (2010) realizaram um estudo que teve como objetivo examinar as inter-relações entre liderança de alta gerência, cultura organizacional e práticas de recursos humanos $(\mathrm{RH})$, e seus efeitos associativos no desempenho organizacional. Com base na teoria da aprendizagem organizacional, desenvolveram e testaram dois modelos causais diferentes: (1) um modelo de fluxo de aprendizagem em avanço, no qual a liderança de apoio da alta administração criaria uma cultura comunitária e práticas de RH dentro das organizações; e (2) um modelo de fluxo de aprendizagem de feedback, no qual a comunidade apoiaria a prática de liderança pela administração de alto escalão e práticas de $\mathrm{RH}$ dentro de uma empresa. Os resultados de modelagem de equações estruturais (SEM) para uma amostra de 225 pequenas e médias empresas japonesas no Japão apoiaram o segundo modelo, no qual a predominância de uma cultura comunitária dentro da empresa é um antecedente da liderança de suporte da alta gerência. O que, por sua vez, exige uma prática de avaliação baseada no desempenho e, eventualmente, leva a um melhor desempenho organizacional em termos de indicadores objetivos das taxas de rotatividade e absenteísmo e da produtividade da força de trabalho. As descobertas foram usadas para discutir o papel da liderança da alta administração em uma determinada cultura organizacional do ponto de vista da aprendizagem organizacional. Limitações e orientações para futuras pesquisas também foram discutidas. 
Os autores Gang, Courtright \& Colbert (2011) referem que embora a liderança transformacional tenha sido estudada extensivamente, a magnitude da relação entre a liderança transformacional e o desempenho dos seguidores nos tipos de critérios e níveis de análise permanece incerta. Com base em 117 amostras independentes de 113 estudos primários, o atual estudo meta-analítico mostrou que a liderança transformacional estava positivamente relacionada ao desempenho do nível individual de seguidor entre os tipos de critério, com um relacionamento mais forte para o desempenho contextual do que para o desempenho da tarefa na maioria dos ambientes de estudo. Além disso, a liderança transformacional estava positivamente relacionada ao desempenho nos níveis de equipe e organização. As análises de regressão meta-analítica e de importância relativa mostraram consistentemente que a liderança transformacional teve um resultado de aumento sobre a liderança transacional (recompensa contingente) na previsão do desempenho contextual em nível individual e do desempenho em nível de equipe. Ao contrário da nossa expectativa, no entanto, nenhum efeito de aumento da liderança transformacional sobre a recompensa contingente foi encontrado na previsão do desempenho da tarefa no nível individual. Em vez disso, a recompensa contingente explicou a variação incremental no desempenho da tarefa no nível individual além do explicado pela liderança transformacional.

Quanto ao estilo de liderança, a cultura organizacional e o comprometimento com o trabalho Muhammad Rafiq Awan, Khalid Mahmood, (2010) realizaram um estudo nas bibliotecas universitárias que teve como objetivo explorar o estilo de liderança, a cultura organizacional e o comprometimento com 0 trabalho nas bibliotecas universitárias do Paquistão e as relações entre eles. Foi utilizado um questionário estruturado desenvolvido e auto-administrado a 115 bibliotecários profissionais. As hipóteses foram testadas por meio do teste $t$, qui-quadrado de Pearson e ANOVA. Resultados - Os resultados mostram que os profissionais da biblioteca não eram muito sensíveis sobre qualquer relação entre essas três variáveis em seu local de trabalho. A maioria dos profissionais percebeu que seus principais bibliotecários tinham um estilo de liderança absolutado e as bibliotecas inclinan-se a adotar uma cultura burocrática e de realização. A maioria dos profissionais da biblioteca parecia estar 
altamente comprometida com suas organizações. Isso significa que eles favoreceram a cultura orientada para resultados. A pesquisa limitou-se a bibliotecas universitárias na província de Punjab, no Paquistão, e na capital federal, Islamabad. Originalidade / valor - O estudo é útil para entender o estilo de liderança, a cultura organizacional e o comprometimento com o trabalho em bibliotecas universitárias.

\section{CONCLUSÃO}

A presente pesquisa foi desenvolvida com o objetivo de oferecer ao leitor uma síntese do conhecimento produzido, no período 2009 a 2019 sobre aprendizagem organizacional no desempenho dos líderes. Foi estabelecido como objetivo central da pesquisa proceder através da Revisão Integrativa da Literatura (RIL), que aborda como tópico aprendizagem organizacional na performance dos líderes.

Apesar das respostas encontradas para a questão desta investigação, destaca-se sua natureza de conjectura prévia, visando o recorte determinado no presente artigo, que limitou a demonstração de 10 trabalhos, entre artigos, dissertações e teses. Ademais, são anexados os padrões identificados que não aparentam dialogar entre si. A determinação de variáveis aparece em níveis distintos em diferentes investigações, o que não facilita o esforço da projeção do diálogo. Uma resposta mais bem desenvolvida à segunda questão de pesquisa deste artigo depende de maior vigor em levantamento bibliográfico, incluindo trabalhos desenvolvidos a partir de métodos diferentes de pesquisa em outro momento para verificar se foram produzidas outras pesquisas com este tema.

A falta de trabalhos extensos sobre desempenho organizacional e aprendizagem organizacional colaborou para que a dimensão de tempo não fosse devidamente explorada como um todo, constituindo assim, uma lacuna nas investigações na área, visto que não se estabeleceu a impressão no tempo ou a sustentabilidade dos avanços no desempenho de liderança, ocasionados pela adesão de processos e práticas da aprendizagem organizacional. 
Além disso, por desconhecimento, surge uma inconsistência de programas de desenvolvimento de pessoas endereçado a gestores e funcionários. Supostamente, faltam pesquisas direcionadas para responder questões críticas que realmente gerem práticas baseadas em evidência cientifica.

Apesar destas limitações, pensa-se, no entanto, que os resultados obtidos e as conclusões alcançadas com esta investigação poderão constituir-se como um contributo valioso ao permitir compreender a problemática da relação ente aprendizagem organizacional e liderança.

Uma sugestão de investigação futura é a aplicação desta investigação, após um período de tempo, de forma a confirmar se a organização em estudo evoluiu no sentido de se aproximar de um alto nível de desempenho da aprendizagem organizacional. Outra sugestão prende-se com a realização desta investigação através da observação direta o que permitiria um estudo mais pormenorizado por analisar quais as variáveis que contribuem para as diferenças observadas.

\section{REFERÊNCIAS}

BAKER, Willian; SINKULA, James. The synergetic effect of market orientation and learning orientation on organizational performance. Journal of the Academy of Marketing Science, v.27, n.4, p.411-427, 1999.

BOTELHO, Louise de Lira Roedel ; CUNHA,Cristiano Castro de Almeida . O método da revisão integrativa nos estudos organizacionais. Gestão e Sociedade. Belo Horizonte,v.5, n. 11, p. 121-136 · maio-ago. 2011 ISSN 1980-5756. Disponível em:<http://www.gestaoesociedade.org/gestaoesociedade/article/view/1220/906>. Acessado em: 05/01/2019.

CANTALONE, Roger; CAVUSGIL, Tamer;_ZHAO, Yushan . Learning orientation, firm innovation apability, and firm performance. Industrial Marketing Management, v.31, n.6, p.515-524, 2002. 
CUNHA, Cláudia. (COORD.) (2014). Manual de revisão bibliográfica sistemática integrativa: A pesquisa baseada em evidências. Grupo Ânima de Educação. Belo Horizonte, MG: Ed. Grupo Ânima. disciplinas. Disponível em: <nucleoead.com.br/pdf/anima_tcc/gerais/mauais/manual_revisao.pdf.>.

DAVENPORT, Thomas; PRUSAK, Laurence. Conhecimento empresarial: como as organizações gerenciam o seu capital intelectual. 4. ed. Tradução de Lenke Peres. Rio de Janeiro: Campus, 1998. 237 p.

FAUSTIN, Catarina Mafalda dos Santos. A influência das competências de coaching do líder no empenhamento afetivo e desempenho dos colaboradores. Dissertação Mestrado em Gestão Leiria. Escola Superior de Tecnologia e Gestão do Instituto Politécnico de Leiria, 2017.

FRANKLIN, Daniel, D. Corporate social responsibility. The Economist. Recuperado em 22 janeiro, 2008. Disponível em: <http://www.economist.com/specialreports/displ aystory.cfm?story_id=10491077>.

Gil, M. (2005). Panorama da deficiência no Brasil. São Paulo: Rede Saci. Recuperado em 30 janeiro, 2005, de http://www.saci.org.br Grupo de Referência e Apoio à Cidadania Empresarial. (2005). A integração de pessoas com deficiência no mercado de trabalho: como actuar, Lisboa.

GANG Wang; OH, In.-Sue; COURTRIGHT, Stephen. \& COLBERT, Amy. (2011). Transformational Leadership and Performance Across Criteria and Levels: A MetaAnalytic Review of 25 Years of Research. Group \& Organization Management, 36(2), 223-270. Disponível em: <https://doi.org/10.1177/1059601111401017>.

GARVIN, David. Construindo a organização que aprende. Gestão do conhecimento. Harvard Business Review. Rio de Janeiro: Campus, 2001

HÖRBE, Tatiane de Andrade Neves. Aprendizagem organizacional, estrutura organizacional e estilo de liderança: o caso de uma empresa ganhadora do prêmio nacional da qualidade - PNQ Dissertação (Mestrado em Administração) - 
Universidade Federal de Santa Maria, Santa Maria, 2016. Disponível em: $<$ http://repositorio.ufsm.br>.

OLIVEIRA, José Puppim (2008). Empresas na sociedade: sustentabilidade e responsabilidade social. Rio de Janeiro: Elsevier

JUNG, Yuhee \& TAKEUCHI, Norihiko. Performance implications for the relationships among top management leadership, organizational culture, and appraisal practice: testing two theory-based models of organizational learning theory in Japan. The International Journal of Human Resource Management, 21:11,19311950, DOI: 10.1080/09585192.2010.505093, 2010.

KHANDEKAR, Aradhana; SHARMA, Anuradha (2006) "Aprendizagem e desempenho organizacional", Educação + Formação , vol. 48 No. 8/9, pp. 682-692

KREITLON, Maria Priscilla. (2004). A ética nas relações entre empresas e sociedade: fundamentos teóricos da, responsabilidade social empresarial. Anais do Encontro Anual da Associação Nacional de Pós-graduação e Pesquisa em Administração, Curitiba, PR, Brasil, 28.

LEOPOLDINO, Cláudio Bezerra; LOIOLA, Elizabeth. Desempenho organizacional e aprendizagem organizacional: o que podemos aprender sobre essa relação? In XXXIV Anais do Encontro Nacional da Associação Nacional de Pós-Graduação e Pesquisa em Administração, Rio de Janeiro, RJ, Brasil, 2010.

LINS, Maria Paula Beatriz Estellita. Predição de competências de liderança a partir do uso de estratégias de aprendizagem, horas de treinamento e motivação para aprender. Universidade de Brasília Instituto de Psicologia Programa de Pósgraduação em Psicologia Social, do Trabalho e das Organizações Mestrado Lins, M. P. B.E., D.F, 2011.

LOIOLA, Elizabeth; BASTOS, Antonio Virgilio Bittencourt . A Produção Acadêmica sobre Aprendizagem Organizacional no Brasil RAC, v. 7, n. 3, Jul./Set. 2003. 
MUHAMMAD, Rafiq Awan ; MAHMOOD, Khalid." among leadership style, organizational culture and employee commitment in university libraries, Library Management, Vol. 31 Issue: 4/5, pp.253-266, 2010. Disponível em: <http://doi.org/10.1108/01435121011046326>.

PEREIRA, B. C. B. Empreendedorismo: habilidade para indivíduos e prática para organizações. Dissertação apresentada ao Programa de Pós-Graduação Stricto Sensu em Gestão do Conhecimento e Tecnologia da Informação da Universidade Católica de Brasília, como requisito parcial para obtenção do Título de Mestre em Gestão do Conhecimento e Tecnologia da Informação. Brasília - DF 2016.

PERIN, Marcelo Gattermann; SAMPAIO, Cláudio Hoffmann; FALEIRO, Sandro Nero. O impacto da orientação para o mercado e da orientação para aprendizagem sobre a inovação de produto: uma comparação entre a indústria eletroeletrônica e o setor de ensino universitário de administração. Revista de Administração Contemporânea, v.8, n.1, p.79-103, 2004.

PIEDADE, Adrian Guido Silva A influência da liderança no desempenho de atendentes em Contact Centers: o Caso Contax S/A. Dissertação aprovada como requisito parcial para obtenção do grau de Mestre Profissional em Administração. Universidade Federal da Bahia - UFBA, 2011.

RAUBER, Moacir Jorge. Coaching de Socialização: uma nova aplicação para o coaching como ferramenta de desenvolvimento pessoal. Tese de doutoramento em Ciências Empresariais, Escola de Economia e Gestão. Braga: Universidade do Minho, 2017.

REGO, Arménio CUNHA, Miguel Pina e CLEGG, Stewart Liderança Global Virtuosa. Revista de Psicologia, Fortaleza, v. 1 n. 1, p. 9-32, jan./jun. 2010.

RHEE, Jaehoon.; PARK, Taekyung.; LEE, Do Hyung. Drivers of innovativeness and performance for innovative SMEs in South Korea: mediation of learning orientation. Technovation, v.30. n.1, p.65-75, 2010. 
ROBBINS, Stepen, P . A nova administração. 1ํ Edição. São Paulo: Saraiva,2014.

ROTHER, E. T. (2007). Revisão sistemática X Revisão narrativa. Acta Paulista de Enfermagem, 20(2), v-vi.

SANTOS, Joana Fonseca de Oliveira. A formação como instrumento da mudança: a caso Crowne Plaza Porto em processo de rebranding. Trabalho Final de Mestrado apresentado à Universidade Católica Portuguesa para obtenção do grau de Mestre em Gestão de Recursos Humanos. Universidade Católica Portuguesa, Porto, 2017.

SCHOMMER, Paula Chies (2009). Responsabilidade socioambiental. MBA Executivo em Gestão e Negócios do Desenvolvimento Regional Sustentável. Brasília: Universidade Corporativa Banco do Brasil; Universidade Corporativa CAIXA.

SENGE, Peter. A quinta disciplina. 10 ed. São Paulo: Editora Best Seller, 1999.

SILVA, Alexsandra Lessa.; CRAVO, Julian Ribeiro.; TEIXEIRA, Tatiani Fernandes. A gestão estratégica de pessoas como fator principal de desenvolvimento humano e empresarial: estudo de caso da empresa Áurea Alimentos. Revista Maiêutica, Indaial, v. 4, n. 1, p. 111-120, 2016.

SOUZA, Marcela Tavares, DA SILVA, Michelly Dias, \& DE CARVALHO, Rachel. (2010). Revisão integrativa: o que é e como fazer. Einstein (São Paulo), 8, 102-106.

Enviado: Julho, 2019.

Aprovado: Agosto, 2019. 